\title{
From Yokohama to Sendai: Approaches to Participation in International Disaster Risk Reduction Frameworks
}

\author{
Arielle Tozier de la Poterie ${ }^{1} \cdot$ Marie-Ange Baudoin ${ }^{2}$
}

Published online: 16 June 2015

(C) The Author(s) 2015. This article is published with open access at Springerlink.com

\begin{abstract}
Taking the importance of local action as a starting point, this analysis traces the treatment of participation of local and community actors through the three international frameworks for disaster risk reduction (DRR): the Yokohama Strategy and Plan of Action for a Safer World, the Hyogo Framework for Action 2005-2015, and the Sendai Framework for Disaster Risk Reduction 2015-2030 (SFDRR). The study finds a concerning shift away from valuing local community input and toward promoting technological advances. Community actors went from valued partners with their own expertise and relevant beliefs in Yokohama Strategy to "aid recipients" to whom tailored risk information must be transmitted (in SFDRR). This shift may reflect the top-down nature of negotiated international agreements or a broader shift toward investments in technological solutions. Whatever the cause, given widespread recognition of the importance of local knowledge and participation and growing recognition of the importance of intra-community differences in vulnerability, it suggests the need for reconsideration of both the discourse and the practice of involving community-level actors in DRR planning and implementation.
\end{abstract}

Arielle Tozier de la Poterie

arielle.tozierdelapoterie@colorado.edu

Marie-Ange Baudoin

marieange007@gmail.com

1 Consortium for Capacity Building, Institute of Arctic and Alpine Research (INSTAAR), University of Colorado, Boulder, CO 80309-0450, USA

2 Researcher \& Course Convener African Climate \& Development Initiative (ACDI), University of Cape Town, Geological Sciences Building, Rondebosch, Cape Town 7701, South Africa
Keywords Community participation - Disaster risk reduction - Discourse analysis - International frameworks

\section{Introduction}

This year (2015) is critical to the renewal of many international agreements. Three top-down, international meetings that pertain to sustainable development will be renegotiated, redefining global priorities for reducing vulnerability and building resilience to present and future disasters as well as for overall poverty reduction for the next $10-15$ years. The first of these processes, the World Conference on Disaster Risk Reduction (WCDRR), took place in March in Sendai, Japan. The WCDRR will be followed by a gathering in New York in September 2015 to define voluntary Sustainable Development Goals (SDGs) - the successor to the Millennium Development Goals (MDGs) — and then by the 21st United Nations Framework Convention on Climate Change Conference of Parties (COP21) in November/December 2015, which will seek legally binding agreements on climate change mitigation and adaptation.

Climate change is widely anticipated to alter the frequency and intensity, as well as change the location, of natural hazards, which can already affect development gains (Basher 2006; IPCC 2012, 2014; Kelman 2015). There are recurring calls to be more efficient when managing the impacts of recurring natural hazards by integrating both disaster risk reduction (DRR) and climate change adaptation (CCA) with development activities (Glantz et al. 2014; Kelman et al. 2015). This trend is also promoted among international conventions for DRR. For instance, the Hyogo Framework for Action 2005-2015 Mid-Term Review acknowledged DRR as a development issue (UNISDR 2011). The recent Sendai Framework for Disaster Risk Reduction (SFDRR), which is 
the main outcome of the WCDRR held in March 2015, recognizes that "Disasters, many of which are exacerbated by climate change and increasing in frequency and intensity, significantly impede progress towards sustainable development" (UNISDR 2015, p. 4).

In order to better cope with an uncertain future, calls to learn lessons from research and experience have been made as a means to improving development outcomes in the context of global change (Carlsson and Wohlgemuth 2000; UNISDR 2010; World Bank 2014; Glantz et al. 2014). One common lesson is the importance of local action for effective risk management, whether in the form of participation, incorporation of indigenous knowledge, or communitybased DRR. Similarly, international frameworks for DRR recognize the need to involve local actors and communities in order to successfully increase resilience to disaster risks and climate change impacts (UNISDR 2005, 2015). For decades the development community has recognized the importance of local context and community and individual participation in shaping the outcomes of development and DRR projects. Properly executed participation of project beneficiaries in planning and implementation is believed by many to contribute to the sustainability and relevance of interventions (Hickey and Mohan 2004) and to the empowerment of local people (Chambers 2008).

Although community-based and participatory DRR are widely practiced, community input into DRR can take many forms, from participation in priority setting and actual decision making to top-down "education" about hazards (Arnstein 1969; Pretty 1995; White 1996; Chambers 2008). These discrepancies may explain why scholars and practitioners have both touted community participation as a means to better development outcomes (Chambers 1994; Manikutty 1997; Hickey and Mohan 2004) and demonized it as a "buzzword" used to depoliticize projects, legitimize technocratic solutions (Chhotray 2004), and clandestinely reinforce existing power relations at both the local and the international levels (White 1996; Cooke and Kothari 2001; Mosse 2004; Parfitt 2004; Cornwall and Brock 2005; Leal 2007). Despite disagreements about the ways in which local communities should be involved, recent research reaffirms the need to understand local context and individual motivations when planning and implementing DRR (Carr 2014; Carr and Owusu-Daaku 2015; Roncoli et al. 2008).

Taking the importance of local action as a starting point, this article looks at the treatment of participation, the incorporation of indigenous knowledge, and local context-factors widely cited as being essential to both development and DRR - across the major frameworks for disaster (risk) reduction negotiated over the last two decades: the Yokohama Strategy and Plan of Action for a Safer World, the Hyogo Framework for Action 2005-2015 (HFA), and the Sendai
Framework for Disaster Risk Reduction 2015-2030 (SFDRR). The goal is to highlight shifts in the way international frameworks relate to the local level as a pathway to improve effectiveness of DRR action plans. We chose to focus on the international discourse developed around DRR, and not on the implementation of DRR strategies; while the latter has been the topic of many research articles and official reports so far (Hellmuth et al. 2007; Senaratna et al. 2014; Glantz et al. 2014), the former has not yet been at the core of many studies. Our approach is unique-it offers a thorough text analysis of major international DRR frameworks that is currently missing in the scientific literature. Our work is also new since SFDRR was released a few months ago, and its content has not yet been at the core of many in-depth analyses. Understanding the meaning and nuances in international discourse is critical, as conventions and frameworks at this scale tend to guide the flow of funding and project implementation for a considerable period (often a decade or more).

We draw on the existing literature on participation in development and DRR, and on what evidence there is regarding Yokohama, HFA, and SFDRR, to evaluate how top-down frameworks relate to the local level by involving communities and other local actors. The article concludes by considering the implications of these findings for the treatment and inclusion of community actors in forthcoming SDGs and climate negotiations (COP21) in ways that better reflect realities and needs at a grassroots scale.

\section{Method, Scope and Limits}

This study is a desk review of the existing literature pertaining to HFA combined with in-depth, comparative textual analysis of the three frameworks (Yokohama, Hyogo, and Sendai). For the literature review, we searched for published research on participation in DRR more generally, as well as for those analyzing implementation of HFA at the local and community levels. Keywords included Hyogo Framework for Action, participation, and communitybased. We compared the texts from the three frameworks, examined changes in language, framing, and emphasis as well as analyzed the frequency in their use of certain words (for example, community, indigenous, technology). We conclude the study with recommendations based upon the existing literature on the role of participation in DRR and discuss implications for SFDRR moving forward. A major limitation of this study is that, rather than looking first hand at implementation of HFA and how community-level actors are involved in a particular context, we draw our data only from the text of the frameworks and from what has already been written about the participation of communities in HFA implementation. 


\section{International Strategies and Frameworks for Action}

This section presents the results of an in-depth textual analysis focused on the three international frameworks for DRR: the Yokohama Strategy and Plan of Action for a Safer World; the Hyogo Framework for Action 2005-2015 (HFA); and the Sendai Framework for Disaster Risk Reduction 2015-2030 (SFDRR). The aim is to assess each plan's treatment of local-level implementation of DRR through the promotion of community participation and involvement of local actors as part of the disaster risk management process.

\subsection{The Yokohama Strategy}

The Yokohama Strategy and Plan of Action for a Safer World was adopted in 1994 following the United Nations World Conference on Natural Disaster Reduction, held in Yokohama, Japan. It is the first document providing guidelines at the international level for preparation for and prevention and mitigation of disaster impacts.

The Yokohama Strategy was a product of the International Decade for Natural Disaster Reduction (1990-2000) and, more specifically, of the World Conference on Natural Disaster Reduction held in 1994. These two international events acknowledged the importance of community involvement in DRR, which is also reflected in the following paragraph, extracted from the Yokohama Strategy (IDNDR 1994, p. 4):

Active participation should be encouraged in order to gain greater insight into the individual and collective perception of development and risk, and to have a clear understanding of the cultural and organizational characteristics of each society as well as of its behavior and interactions with the physical and natural environment. This knowledge is of the utmost importance to determine those things which favour and hinder prevention and mitigation or encourage or limit the preservation of the environment for the development of future generations, and in order to find effective and efficient means to reduce the impact of disasters.

This document offers a set of principles on which DRR strategy should be based, according to the international community of the mid-1990s. Similar to the above-extracted paragraph, other sections of the Yokohama Strategy suggest an involvement of local actors in risk management practice, valuing their experience in this field as well as a need to ensure the DRR process is placed in their hands. Table 1 presents the results of an in-depth analysis of
Yokohama Strategy's principles and the extent to which they relate to community participation.

The Yokohama Strategy especially focused on improving coping mechanisms in order to better cope with and recover from disasters' impacts. To facilitate an easy and fast recovery process, this strategy valued the knowledge and experience in managing emergencies that exists at the local level among at-risk communities. The following decade (2000s) represents a shift in the way DRR is perceived, moving from a strong focus on coping capacities and relief interventions to an increased attention brought to risk preparedness and prevention (Baudoin and WoldeGeorgis 2015).

\subsection{The Hyogo Framework for Action 2005-2015}

The notion of DRR became a popular idea with the World Conference for Disaster Reduction held in Kobe, Hyogo, Japan in mid-January 2005. The conference coincidentally took place in the aftermath of the 2004 tsunami in the Indian Ocean, which affected millions of people and raised public awareness about so-called "natural" disasters, their risks, and their serious impacts. The outcome of the conference, the Hyogo Framework for Action 2005-2015 (HFA), is probably the most significant international document popularizing the notion of DRR. The 2000-2009 decade is also critical in terms of shifting concerns around disaster issues, with an increased focus on risk preparedness. This evolution of focus is present both in academia (Holloway 2003; Vermaak and van Niekerk 2004) and among major organizations working in the field of DRR (UNISDR 2012; USAID 2012).

The IDNDR was completed at the end of 1999, but not without follow-up strategies. Recognition of the increased impacts of disasters led to the creation of the International Strategy for Disaster Reduction (UNISDR) in December 1999, which serves as secretariat for the International Strategy for Disaster Reduction (ISDR) system and was adopted by the United Nations Member States in 2000. The goal of the ISDR strategic framework is to ensure "the implementation of the International Strategy for Disaster Reduction" (http://www.unisdr.org/) through the promotion of consolidated efforts for international collaboration in order to reduce risk vulnerability (Olowu 2010). The HFA was adopted as part of the ISDR, and its implementation is coordinated by the UNISDR (a United Nations secretariat). It was the first plan that described the detailed processes necessary to reduce disaster risks in various sectors and at different scales.

The concept of DRR as put forth in HFA reflects a stronger focus on risk preparedness and prevention, as opposed to the emphasis on response and recovery during the previous decades. HFA outlines five priorities for action, and offers 
Table 1 Yokohama Strategy recommendations highlighting areas for community involvement

\begin{tabular}{|c|c|}
\hline Recommendation for action & Reference to area for community involvement \\
\hline Plan of Action, Recommendation A & $\begin{array}{l}\text { Express the political commitment to reduce their vulnerability through declaration, legislation, policy } \\
\text { decisions and action at the highest level, which would require the progressive implementation of } \\
\text { disaster assessment and reduction plans at the national and community levels (Section II, A, p. 14) }\end{array}$ \\
\hline Plan of Action, Recommendation Q & $\begin{array}{l}\text { Stimulate genuine community involvement and empowerment of women and other socially } \\
\text { disadvantaged groups at all stages of disaster management programmes in order to facilitate capacity } \\
\text { building, which is an essential precondition for reducing vulnerability of communities to natural } \\
\text { disasters (Section II, Q, p. 15) }\end{array}$ \\
\hline Plan of Action, Recommendation $\mathrm{R}$ & $\begin{array}{l}\text { Aim at the application of traditional knowledge, practices and values of local communities for disaster } \\
\text { reduction, thereby recognizing these traditional coping mechanisms as a valuable contribution to the } \\
\text { empowerment of local communities and the enabling of their spontaneous cooperation in all disaster } \\
\text { reduction programmes (Section II, R, p. 15) }\end{array}$ \\
\hline
\end{tabular}

The structure of Yokohama was different than that of Hyogo or Sendai. In order to conserve space, this table includes only references in the section on recommendations for action

guiding principles and practical means for achieving disaster resilience. Based on a review of the text, Table 2 highlights areas for community involvement in the HFA text.

According to the UNISDR's website (http://www. unisdr.org), HFA aimed to "substantially reduce disaster losses by 2015 by building the resilience of nations and communities to disasters." This means reducing loss of lives and social, economic, and environmental assets when hazards strike. The adoption of the framework was accompanied by the establishment of different tools and platforms designed to help implement DRR at regional, national, and local levels. There is, for instance, a global platform to share experience on DRR among UNISDR parties (Olowu 2010); national platforms were also developed to track efforts in the implementation of DRR strategies made in each country; finally a reporting process was establish through the voluntary submission of national reports on progress regarding the implementation of HFA (Olowu 2010). Through these various tools, the focus was on tracking progress in DRR implementation from the regional to national scales. A similar reporting tool was not set up to assess HFA's implementation at the local level, suggesting limited consideration on the part of the international community as to how to track the communitylevel impacts of these DRR strategies.

\subsection{The Sendai Framework for Disaster Risk Reduction 2015-2030 (SFDRR)}

The HFA was a 10-year action plan, effective from 2005 to 2015. During this decade, disasters around the world continued to produce human, economic, infrastructure, and ecological losses, especially in the most vulnerable and poorest nations (Hellmuth et al. 2007; World Bank 2012; Guha-Sapir et al. 2014; Nicholson 2014). Thus, commitments to support DRR were renewed when HFA came to an end.
Renewed commitment to DRR is reflected in the SFDRR, finalized in Sendai, Japan in March 2015. The new SFDRR is, in theory, built on the lessons learned from the implementation of HFA during the past decade. It comprises a voluntary set of targets and priorities to foster increased resilience to present and future hazards and to prevent setbacks to development as the result of small and large disasters. In addition, SFDRR also intends to reflect new challenges that characterize today's world, namely climate change, increased globalization, and the development of new technologies and expertise in the field of risk prediction and early warning systems (Zia and Wagner 2015). Table 3 presents the outcome of a text analysis focused on SFDRR's four "priority actions" with regard to space for community participation.

As the SFDRR was adopted recently, only the future will tell how these four priorities are put into practice. Thus, our analysis is focused solely on the text of the framework with the objective of analyzing the treatment of community participation and highlighting shifts in discourse compared to the previous international DRR frameworks. In the next section, we present the results of a thorough text analysis and comparison of the three DRR frameworks respectively adopted in Yokohama, Hyogo, and Sendai. The comparative study was conducted in order to shed light on significant differences or change in tone regarding the way international DRR strategies propose to involve local actors as part of the DRR process.

\section{Comparative Textual Analysis of the Three Frameworks}

This study demonstrates that all three frameworks recognize, to some extent, the need to empower or involve local people to participate in DRR in their own communities. But there are important differences in the ways in which this is done in 
Table 2 HFA priorities highlighting areas for community involvement

\begin{tabular}{|c|c|}
\hline Priority action & Reference to area for community involvement \\
\hline $\begin{array}{l}\text { 1. Ensure that disaster risk } \\
\text { reduction is a national and } \\
\text { a local priority with a } \\
\text { strong institutional basis } \\
\text { for implementation }\end{array}$ & $\begin{array}{l}\text { Recognize the importance and specificity of local risk patterns and trends, decentralize responsibilities and } \\
\text { resources for disaster risk reduction to relevant sub-national or local authorities, as appropriate (Activity i, d, } \\
\text { p. 6) } \\
\text { Promote community participation in disaster risk reduction through the adoption of specific policies, the } \\
\text { promotion of networking, the strategic management of volunteer resources, the attribution of roles and } \\
\text { responsibilities, and the delegation and provision of the necessary authority and resources (Activity iii, h, p. 7) }\end{array}$ \\
\hline $\begin{array}{l}\text { 2. Identify, assess and } \\
\text { monitor disaster risks and } \\
\text { enhance early warning }\end{array}$ & $\begin{array}{l}\text { Develop, update periodically and widely disseminate risk maps and related information to decision-makers, the } \\
\text { general public and communities at risk in an appropriate format (Activity i, a, p. 7) } \\
\text { Develop systems of indicators of disaster risk and vulnerability at national and sub-national scales that will } \\
\text { enable decision-makers to assess the impact of disasters on social, economic and environmental conditions and } \\
\text { disseminate the results to decision-makers, the public and populations at risk (Activity i, b, p. 7) } \\
\text { Develop early warning systems that are people centered, in particular systems whose warnings are timely and } \\
\text { understandable to those at risk, which take into account the demographic, gender, cultural and livelihood } \\
\text { characteristics of the target audiences, including guidance on how to act upon warnings, and that support } \\
\text { effective operations by disaster managers and other decision makers (Activity ii, d, p. 7) }\end{array}$ \\
\hline $\begin{array}{l}\text { 3. Use knowledge, innovation } \\
\text { and education to build a } \\
\text { culture of safety and } \\
\text { resilience at all levels }\end{array}$ & $\begin{array}{l}\text { The information should incorporate relevant traditional and indigenous knowledge and culture heritage and be } \\
\text { tailored to different target audiences, taking into account cultural and social factors (Activity i, a. p. 9) } \\
\text { Promote community-based training initiatives, considering the role of volunteers, as appropriate, to enhance } \\
\text { local capacities to mitigate and cope with disasters (Activity ii, } 1, \text { p. 10) } \\
\text { Ensure equal access to appropriate training and educational opportunities for women and vulnerable } \\
\text { constituencies; promote gender and cultural sensitivity training as integral components of education and } \\
\text { training for disaster risk reduction (Activity ii, m, p. 10) }\end{array}$ \\
\hline $\begin{array}{l}\text { 4. Reduce the underlying risk } \\
\text { factors }\end{array}$ & $\begin{array}{l}\text { No real mention of community level. This section is mostly about integrating DRR with planning and other } \\
\text { sectors }\end{array}$ \\
\hline $\begin{array}{l}\text { 5. Strengthen disaster } \\
\text { preparedness for effective } \\
\text { response at all levels }\end{array}$ & $\begin{array}{l}\text { Develop specific mechanisms to engage the active participation and ownership of relevant stakeholders, } \\
\text { including communities, in disaster risk reduction, in particular building on the spirit of volunteerism (Activity } \\
\text { f, p. 13) } \\
\text { The spirit of this priority is about strengthening all levels }\end{array}$ \\
\hline
\end{tabular}

each of the frameworks, as well as a marked shift over time from respectful inclusion of local communities and knowledge toward a more top-down approach to DRR.

\subsection{From Yokohama to Hyogo: Increased Top- Down Perspective on Community Involvement}

Written over two decades ago, the Yokohama Strategy already reflected the spirit of much of what has subsequently been written about indigenous and traditional knowledge and local participation (see Sect. 3.1). This framework offers clear articulation of the importance of nuanced understandings of how people perceive and respond to hazards given their belief systems, priorities, and the resources at their disposal. This echoes much of the academic literature on the importance of understanding local perceptions of vulnerability and motivations and constraints to action (Roncoli et al. 2008; Carr 2014; Carr and Owusu-Daaku 2015). It also relates to the need to build partnerships among scientists, development practitioners, and local communities that ensure that all relevant parties are heard and enabled to influence the DRR process (Mercer et al. 2008).
In its language, the Yokohama Strategy values understanding the local context as a key component of planning and implementing DRR initiatives. Throughout the Yokohama Strategy there are calls to strengthen DRR efforts by "mobilizing" traditional expertise and increasing communities' self-confidence through "recognition and propagation of traditional knowledge, practices and values" (IDNDR 1994, p. 11). The desired empowerment of local communities comes through understanding local circumstances and harnessing local expertise. Respect for and cooperation with local actors are presented as "essential preconditions for reducing vulnerability" (IDNDR 1994, p. 15). Such respect and recognition of the importance of a nuanced understanding of local circumstances seems lost in the HFA (UNISDR 2005) and in SFDRR (UNISDR 2015) adopted during the decades following the Yokohama Strategy.

Although the brief review of the Yokohama Strategy in the first pages of the HFA reiterates the importance of "involving people in all aspects of DRR in their own local communities" (UNISDR 2005, p. 2), in the HFA there is a notable shift in language and tone. Reference to indigenous knowledge in the HFA is made in the context of 
Table 3 SFDRR priorities highlighting areas for community involvement

\begin{tabular}{|c|c|}
\hline Priority action & Reference to area for community involvement \\
\hline 1. Understanding disaster risk & $\begin{array}{l}\text { Ensure the use of traditional, indigenous and local knowledge and practices, as appropriate, to complement } \\
\text { scientific knowledge in disaster risk assessment and the development and implementation of policies, } \\
\text { strategies, plans and programmes of specific sectors, with a cross-sectoral approach, which should be tailored } \\
\text { to localities and to the context (Activity i, p. 11) } \\
\text { Enhance collaboration among people at the local level to disseminate disaster risk information through the } \\
\text { involvement of community-based organizations and non-governmental organizations (Activity o, p. 11) }\end{array}$ \\
\hline $\begin{array}{l}\text { 2. Strengthening disaster risk } \\
\text { governance to manage } \\
\text { disaster risk }\end{array}$ & $\begin{array}{l}\text { Assign, as appropriate, clear roles and tasks to community representatives within disaster risk management } \\
\text { institutions and processes and decision-making through relevant legal frameworks. Undertake comprehensive } \\
\text { public and community consultations during the development of such laws and regulations to support their } \\
\text { implementation (Activity f, p. 13) } \\
\text { Empower local authorities, as appropriate, through regulatory and financial means to work and coordinate with } \\
\text { civil society, communities and indigenous peoples and migrants in disaster risk management at the local level } \\
\text { (Activity h, p. 14) }\end{array}$ \\
\hline $\begin{array}{l}\text { 3. Investing in disaster risk } \\
\text { reduction for resilience }\end{array}$ & $\begin{array}{l}\text { Limited to including at the local level } \\
\text { No mention of directing more money to projects that engage community members }\end{array}$ \\
\hline $\begin{array}{l}\text { 4. Enhancing disaster } \\
\text { preparedness for effective } \\
\text { response, and to "Build } \\
\text { Back Better" in recovery, } \\
\text { rehabilitation and } \\
\text { reconstruction }\end{array}$ & $\begin{array}{l}\text { Empowering women and persons with disabilities to publicly lead and promote gender equitable and universally } \\
\text { accessible response, recovery rehabilitation and reconstruction approaches are key (Introduction, p. 17) } \\
\text { Prepare or review and periodically update disaster preparedness and contingency policies, plans and programmes } \\
\text { with the involvement of the relevant institutions, considering climate change scenarios and their impact on } \\
\text { disaster risk, and facilitating, as appropriate, the participation of all sectors and relevant stakeholders (Activity } \\
\text { a, p. 18) } \\
\text { Invest in, develop, maintain and strengthen people-centred multi-hazard, multisectoral forecasting and early } \\
\text { warning systems, disaster risk and emergency communications mechanisms, social technologies and hazard- } \\
\text { monitoring telecommunications systems. Develop such systems through a participatory process. Tailor them to } \\
\text { the needs of users, including social and cultural requirements, in particular gender. Promote the application of } \\
\text { simple and low-cost early warning equipment and facilities and broaden release channels for natural disaster } \\
\text { early warning information (Activity b, p. 18) }\end{array}$ \\
\hline
\end{tabular}

incorporating it into top-down advisories. More emphasis is placed on considering cultural heritage in order to develop information appropriate for "target" audiences (UNISDR 2005, p. 9) rather than acknowledging and respecting local circumstances and understandings. HFA, of course, includes references to indigenous and traditional knowledge, but the main motivation beyond these allusions does not appear to be because of local knowledge's own value for DRR as was the case in the Yokohama Strategy. Instead interest in traditional knowledge is pursued so that DRR early warning systems, information, and training can be appropriately "tailored" to the audience.

A thorough study of HFA's text indicates that community empowerment is perceived as the result of providing communities with (external, expert) information on vulnerabilities, hazards, and DRR that they can understand, rather than through valuing what people already know about their own vulnerabilities and their personal, often long-term, experience in managing risks. Therefore the tone used in HFA is not one of partnership and collaboration as was put forth in the Yokohama Strategy, but one of how best to incorporate local knowledge to advance the agenda of outside experts and facilitate DRR implementation within certain communities. This point can be illustrated by the following quote:
The information should incorporate relevant traditional and indigenous knowledge and culture heritage and be tailored to different target audiences, taking into account cultural and social factors (UNISDR 2005, p. 9).

The Hyogo Framework for Action 2005-2015 MidTerm Review (UNISDR 2011) advocates consistently for the importance of community involvement in DRR, resilience building, and local implementation of the HFA (for examples, see pp. 10, 43, 63, 82). One set of questions posed to experts contributing to the review specifically requested feedback on community participation in DRR (UNISDR 2011, p. 88). The authors express repeated concerns that "inclusion of gender perspective and effective community participation are the areas where the least progress seems to have been made" (UNISDR 2011, p. 44). They also note that grassroots women's organizations remain marginalized and cut off from the decisionmaking processes. This "lack" of HFA implementation at the local level has lead to "a significant gap between national and local level action" and "very limited" progress at the local level (UNISDR 2011, p. 46). The review also notes that "the notion of differential vulnerability among different societal groups is not adequately 
addressed by the new institutional and legislative arrangements, and there are few examples of local knowledge informing policy" (UNISDR 2011, p. 46).

These findings were supported by external analyses. The Global Network of Civil Society Organisations (GNCSO) and the International Federation of Red Cross and Red Crescent Societies (IFRC) studies examining progress toward HFA participation goals found that communities are still not effectively engaged in DRR decision making (IFRC 2010). In development more broadly, metaevaluations of participatory projects have revealed that because of funding and other processes, key decisions about program implementation need to be made before having consulted with communities (OECD 1997).

The language used in the mid-term review echoes that of the Yokohama Strategy, which advocated greater inclusion of local communities and their knowledge and experience in support of DRR. For instance, the document states that "If development policies and programmes are designed based on self-identified and prioritised needs of vulnerable communities, underlying risks will by necessity be addressed through a multi-sectoral, integrated approach" (UNISDR 2011, p. 49).

The HFA mid-term report also calls attention to the lack of funding to support community implementation, an important impediment to realizing progress at the community level. In the HFA mid-term report, the International Federation of Red Cross and Red Crescent Societies expressed the related concern that "national planning and decision-making often does not take into consideration the needs and capacities of the most vulnerable, so resources and support are not provided to enable and empower those who need it most" (UNISDR 2011, p. 49). Without funding streams to "explicitly put disaster risk reduction on the agenda of local governments, it is unlikely to achieve the mainstreaming required for effective local action unless local voices are sufficiently strong to advocate for a prioritization of resources at the local government level in favour of disaster risk reduction" (UNISDR 2011, p. 48). These statements raise the real concern that without better funding, local-level implementation is likely to continue to lag behind national and international plans.

Similar issues with lack of funding at the local level are reported in the academic literature. For instance, in their analysis of HFA implementation in Indonesia, Djalante et al. (2012) found that one of the barriers to improving DRR at the local scale is a lack of financial resources available to foster risk preparedness and recovery measures. The fragmentation between DRR and other development issues, such as poverty, lead these potentially complementary foci to compete with and draw attention away from each other. Such competition, rather than collaboration, within local institutions is a significant barrier to improving resilience in developing nations. In fact, in poorer nations development problems are often the central focus of local stakeholders (governmental and nongovernmental). For instance, in an analysis of how local budget is allocated by South African municipalities, Taylor, Cartwright, and Sutherland (2013) point out that resources available for environmental management are often close to zero as local entities tend to focus on salient problems such as poverty, inequity, and unemployment, without realizing that a better management of natural resources is also important for meeting development goals. The same observation can apply to DRR, as building risk resilience among local communities is also part of the development process.

Due to lack of funds, local entities currently tend to rely on national support and international help to face disaster risks or to recover from their impacts (Djalante et al. 2012). Yet, local stakeholders are at the frontline of disaster risk management and are well positioned to coordinate local actions and build community capacities (Taylor et al. 2013; Baudoin et al. 2014). This observation calls for building local governments' capacities to deal with disaster risks and for increasing local actors' involvement in the risk reduction process. This finding is supported by research in Africa, which also found that increased participation of civil society - those who can identify local needs and priorities-is necessary to improve DRR effectiveness, making it more context-specific and ensuring ownership (as opposed to just a partnership) in the DRR process (Olowu 2010).

Drawing on these lessons in order to "ensure more emphasis on local implementation of the HFA," the midterm report makes several recommendations for the HFA moving forward, and presumably for future frameworks (SFDRR) (UNISDR 2011, p. 61). The recommendations include "mapping local dimensions of hazards and vulnerabilities," "two-way communication between local and national levels," and "strengthening participatory planning approaches" (UNISDR 2011, p. 63). These lessons reinforce the need for more genuine engagement of international and national actors with community actors in order to build resilience at the local level.

Some may see HFA as one of the impetuses to promote a greater participatory approach in DRR (Pelling 2007), but our text analysis highlights gaps in the way this framework promotes involvement and inclusion of local governmental and nongovernmental actors within the DRR process. An increased collaboration among local governments and communities would help support DRR planning at this scale (Mercer et al. 2008). This was recognized in academia and in the mid-term review of HFA. Using existing lessons, such as those put forth in HFA mid-term review or those extracted from past disaster experiences, would 
contribute to improving future frameworks aimed at reducing disaster risks (Glantz et al. 2014). Unfortunately the language used in SFDRR does not reflect a mainstreaming of existing lessons, despite calls found in the literature and the HFA mid-term review.

\subsection{SFDRR: Increased Focus on Technology, Less Emphasis on Local Knowledge's Value for DRR}

Despite the cautions in the HFA mid-term review, SFDRR appears to make an even more pronounced shift toward top-down advocacy of a DRR agenda rather than a shift toward more meaningful partnerships with local actors. Like HFA, SFDRR mentions the need for "people-centered" DRR, as well as engagement and partnership with "all of society" and "special attention to people disproportionately affected by disasters, especially the poorest" (UNISDR 2015, p. 8). This support entails providing incentives, however, "complementing" scientific knowledge with local knowledge "where appropriate," and "disseminating disaster risk information" (UNISDR 2015, p. 11). The framework calls for "assign[ing...] clear roles and tasks to community representatives," language indicative of a top-down approach rather than collaborative processes (UNISDR 2015, p. 1). Verbs like "disseminate" and "tailor" are used more frequently in the latter frameworks than in the Yokohama Strategy, which further reinforces the notion of a one-way flow of knowledge from experts to recipient communities.

The importance placed upon science, technology, and other forms of external "western" expertise relative to discussion of community, traditional knowledge, and involvement solidifies the expert-driven narrative of SFDRR. Although the number of references to community participation and local knowledge remain constant throughout the three frameworks, references to science, technology, and research increase dramatically from Yokohama to Sendai. For example, Yokohama mentions science 10 times, the HFA 9 times, and Sendai 21 times (for a more complete word count, see Table 4). This new trend may reflect an increased focus, at the global scale, on science and technology as the answer to major global problems, such as those posed by disasters and projected climate change impacts (Glantz et al. 2014).

One area of potential progress in SFDRR is the more detailed elaboration of relevant stakeholders. SFDRR contains a section, absent from the other frameworks, on the "Role of Stakeholders." This section specifically highlights the need for the engagement of women, children and youth, persons with disabilities, the elderly, indigenous peoples, and migrants among other civil society actors. Nevertheless, the majority of references to the community level are vague calls for action at "all levels" or including "all stakeholders" without recognizing or addressing the obvious challenges that must be met to foster meaningful participation of community actors, which was made apparent in the HFA mid-term review.

Interestingly, the SFDRR appears to disregard many of the recommendations from the HFA mid-term review. Although the review pointed out that lack of funding is a key impediment to local level implementation, SFDRR Priority 3, "Investing in disaster risk reduction for resilience" does not mention or emphasize channelling funds to lower levels. SFDRR also does not mention two-way communication, feedback, and participatory planning, nor does the SFDRR document suggest how to foster more meaningful engagement among communities in the implementation of SFDRR.

Several interrelated explanations are possible for the SFDRR's failure to reflect feedback from the HFA midterm review. The hierarchical nature of the Third UN WCDRR in Sendai (and perhaps of all international negotiations) makes it difficult for local or communitybased actors to participate in framework negotiations and to speak to the challenges of local-level implementation. Only those with adequate connections to accredited organizations were able to attend the primary sessions in Sendai, and only higher-level officials participated in the negotiations and the drafting of framework language. Public, community, and NGO actors were largely restricted to public forums and other venues. Hence, by their very nature, such negotiations are dominated by state and regional actors who likely have less of a grasp on locallevel implementation and may be less inclined to broach important questions of how to create more meaningful connections across scales. Whatever the cause, given the poor record of engagement over the last 20 years and the repeated calls for improvement, lack of further specification - or at least recognition of the need to improve communication and feedback across scales-is disappointing and worthy of further investigation.

\subsection{Summary of Comparative Analysis}

The Yokohama Strategy, and to some degree the HFA, valued community empowerment and local expertise as important components of DRR. In the SFDRR, however, most references to community come in the form of passing, vague references to integration of "all levels"-from international to local. Rather than valuing local understandings, the emphasis is on providing support to the most vulnerable (most exposed, poorest communities) in the form of information or other kinds of external, often technology-based, expertise. These references are reminders to integrate local people into top-down plans rather than calls for partnerships and cross-scale collaborations 
Table 4 Word counts from each of the frameworks

\begin{tabular}{|c|c|c|c|}
\hline Word & Yokohama & Hyogo & Sendai \\
\hline People-centered & 0 & 1 (people-centered EWSs) & 2 \\
\hline $\begin{array}{l}\text { Participatory/participation } \\
\text { (community) }\end{array}$ & 3 & 3 (one of these in a footnote) & 2 \\
\hline Stakeholder participation & 0 & 1 & 5 \\
\hline Women & 1 & 2 (one of these in a footnote) & 5 \\
\hline Technology & 6 & 3 (twice transfer) & $\begin{array}{l}18 \text { (sometimes more than once in a } \\
\text { paragraph) }\end{array}$ \\
\hline Technology transfer & 2 & 2 & 6 \\
\hline $\begin{array}{l}\text { Science/scientific } \\
\text { community/scientific }\end{array}$ & 10 & 9 & 21 (often in same paragraph) \\
\hline Gender & 0 & 4 (one of these in footnote) & 4 \\
\hline Research & 5 & $\begin{array}{l}7 \text { (once as heading of an } \\
\text { entire subsection) }\end{array}$ & 14 \\
\hline Indigenous & 1 (NGOs) & 1 (knowledge) & 4 ( 2 as people, 1 as knowledge, 1 as both) \\
\hline Disability/disabilities/disabled & 0 & 1 & 5 \\
\hline Traditional knowledge & $\begin{array}{l}6 \text { (methods, coping } \\
\text { mechanisms, expertise) }\end{array}$ & $\begin{array}{l}1 \text { (at same time as } \\
\text { indigenous knowledge) }\end{array}$ & 3 (twice with indigenous) \\
\hline Technological & 4 (3 as tech disasters) & 2 & $\begin{array}{l}8 \text { (once in footnote, once in overarching } \\
\text { goal/outcome on p. } 7 \text { ) }\end{array}$ \\
\hline All-levels & 3 & 18 & 19 \\
\hline Local level & 1 & 8 & 15 \\
\hline Local context & 0 & 1 & 2 \\
\hline Local needs & 0 & 1 & 3 (1 direct, 2 in spirit) \\
\hline Local communities & 3 & 2 & 4 \\
\hline Community-based & 0 & $\begin{array}{l}2 \text { (once organizations, once } \\
\text { trainings) }\end{array}$ & 2 (both in reference to organizations) \\
\hline $\begin{array}{l}\text { Community (as in local, not } \\
\text { international or scientific) }\end{array}$ & 5 & 4 & 9 \\
\hline Empower & 2 & 1 & 6 \\
\hline Tailor & 0 & 1 & 4 \\
\hline Assign & 0 & 0 & 2 \\
\hline $\begin{array}{l}\text { Disseminate/dissemination (of } \\
\text { information or data) }\end{array}$ & 5 & 9 & 14 \\
\hline
\end{tabular}

that are necessary for improved DRR. The tone suggests that local communities are helpless and in need of externally-driven efforts to prepare for, cope with, and recover from natural hazards; such a position clearly neglects the widely acknowledged fact (in academia and official reports) that local communities have been interacting with their own environments for centuries, thus endowing them with a significant collective experience in risk reduction that is valuable to any DRR framework (Hansen et al. 2011; Baudoin et al. 2014).

Despite the fact that each framework seems to support some kind of community involvement, none of them outlines the mode of participation that will best contribute to achieving framework goals or suggests how to deal with the myriad complications made evident by a literature review on participatory methods. This conclusion is not surprising when we look at the adoption and implementation of other international strategies. For instance, past experience with the Poverty Reduction Strategy Papers (PRSPs), another top-down initiative advocating participatory projects, points to the challenges of getting meaningful participation at all levels (Shivernje 2005; Mpepo and Seshamani 2005). In Kenya, the International Monetary Fund (IMF) failed to enforce provisions requiring engagement of civil society in plan development (Shivernje 2005). In Zambia, civil society was able to secure a prominent role in drafting the PRSP, but the government has been slow to provide it with information necessary to monitor and evaluate progress, and the poor, the program's principal targets, have been excluded from the process 
(Mpepo and Seshamani 2005). In both instances, achieving meaningful participation required more than top-down encouragement. This is a relevant lesson that could have been used to prepare later international conventions and frameworks explicitly targeting vulnerability reduction among the least developed, most hazard-prone, or poorest regions.

Detailed elaboration of how to foster what are likely to be context-specific means of engaging local communities may be an unrealistic expectation for a negotiated, international framework, but the seemingly backward trajectory of the discourse surrounding participation is noteworthy. Given the concern expressed for failures to understand local context and implement HFA at the local scale, the observed shift in language from the Yokohama Strategy to SFDRR, as well as a failure to direct future funding and efforts to understanding place-based vulnerability, raises significant concerns regarding the future management of disaster risks.

\section{Conclusions and Thoughts on Moving Forward}

Partnerships and involvement of relevant local stakeholders and communities are widely recognized as a critical component of successful development and DRR projects and strategies (Chambers 1994; Manikutty 1997; Holloway 2003; Hickey and Mohan 2004; Mercer et al. 2008; Baudoin and Wolde-Georgis 2015). Yet a text analysis of the three major international frameworks for DRR points to a regression over the decades in the way local communities are perceived and valued as partners with relevant expertise for DRR. The three frameworks went from treating local communities as valued partners with their own expertise and relevant beliefs in the Yokohama Strategy to "aid recipients" to whom tailored risk information must be transmitted in SFDRR.

These trends and shifts in the text are important because international frameworks serve as guidelines to direct the flow of funding and the implementation of projects in a specific field. It is unfortunate that valuable lessons are often neglected while negotiating such frameworks. These lessons should serve as a basis to develop the next "international agenda." The SFDRR was supposed to build upon lessons gleaned from HFA and its valuable mid-term review, one of which was the need to better involve local communities, increase finance flows at the local scale, and, overall, improve the bottom-up participatory process within international DRR frameworks. The text analysis clearly indicates that this was not the case. Only the future will tell if implementation of SFDRR is more inclusive of past lessons.
The observed shift away from valuing local community input and toward promoting technological advances may be explained by the nature of top-down negotiations, broader shifts in discourse, the appeal of technological solutions, or the documented difficulties associated with genuine community engagement. Because of the indisputable importance of understanding local perspectives and engaging with local actors in creating successful DRR programs, the reasons for this shift, and for the failure of new frameworks to reflect past lessons regarding local-level participation remain critical areas for further study. Keeping an eye on the upcoming SDGs and forthcoming new climate convention will be important in order to assess if the same shift in language is observed. The outcomes of these next negotiations are also reason for concern with regard to the present text analysis of SFDRR, as these major conventions will likely serve as guidelines to direct climate finance and development aid for the next decade or so.

Open Access This article is distributed under the terms of the Creative Commons Attribution 4.0 International License (http://creativecommons.org/licenses/by/4.0/), which permits unrestricted use, distribution, and reproduction in any medium, provided you give appropriate credit to the original author(s) and the source, provide a link to the Creative Commons license, and indicate if changes were made.

\section{References}

Arnstein, S.R. 1969. A ladder of citizen participation. Journal of the American Institute of Planners 35(4): 216-224.

Basher, R. 2006. Global early warning systems for natural hazards: Systematic and people-centered. Philosophical Transactions of the Royal Society A 364(1845): 2167-2182.

Baudoin, M.-A., A. Cuni-Sanchez, and B. Fandohan. 2014. Small scale farmers' vulnerability to climatic changes in southern Benin: The importance of farmers' perceptions of existing institutions. Mitigation and Adaptation Strategies for Global Change 19(8): 1195-1207.

Baudoin, M.-A., and T. Wolde-Georgis. 2015. Disaster risk reduction efforts in the Greater Horn of Africa. International Journal of Disaster Risk Science 6(1): 49-61.

Carlsson, J., and L. Wohlgemuth. 2000. Learning in development cooperation. Stockholm: Expert Group on Development Issues.

Carr, E.R. 2014. From description to explanation: Using the livelihoods as intimate government (LIG) approach. Applied Geography 52: 110-122.

Carr, E.R., and K.N. Owusu-Daaku. 2015. The shifting epistemologies of vulnerability in climate services for development: The case of Mali's agrometeorological advisory programme. Area. doi:10.1111/area.12179.

Chambers, R. 1994. The origins and practice of participatory rural appraisal. World Development 22(7): 953-969.

Chambers, R. 2008. Revolutions in development inquiry. London: Earthscan.

Chhotray, V. 2004. The negation of politics in participatory development projects, Kurnool, Andhra Pradesh. Development and Change 35(2): 327-352. 
Cooke, B., and U. Kothari (eds.). 2001. Participation: The new tyranny? London: Zed Books.

Cornwall, A., and K. Brock. 2005. What do buzzwords do for development policy? A critical look at "participation", "empowerment" and "poverty reduction". Third World Quarterly 26(7): 1043-1060.

Djalante, R., F. Thomalla, M.S. Sinapoy, and M. Carnegie. 2012. Building resilience to natural hazards in Indonesia: Progress and challenges in implementing the Hyogo Framework for Action. Natural Hazards 62(3): 779-803.

Glantz, M.H., M.-A. Baudoin, A.T. de la Poterie, L. Naranjo, and G. Pierce. 2014. Working with a changing climate, not against itHydro-meteorological disaster risk reduction: A survey of lessons learned for resilient adaptation to a changing climate. Boulder: Consortium for Capacity Building.

Guha-Sapir, D., P. Hoyois, and R. Below. 2014. Annual disaster statistical review 2013: The numbers and trends. Centre for Research on the Epidemiology of Disasters. http://www.cred.be/ sites/default/files/ADSR_2013.pdf. Accessed 1 June 2015.

Hansen, J.W., S.J. Mason, L. Sun, and A. Tall. 2011. Review of seasonal climate forecasting for agriculture in sub-Saharan Africa. Experimental Agriculture 47(S2): 205-240.

Hellmuth, M.E., A. Moorhead, M.C. Thompson, and J. Williams (eds.). 2007. Climate risk management in Africa: Learning from practice. New York: Columbia University's International Research Institute for Climate and Society (IRI).

Hickey, S., and G. Mohan. 2004. Toward participation as transformation: Critical themes and challenges. In Participation-From tyranny to transformation?, ed. S. Hickey and G. Mohan, 3-24. London: Zed Books.

Holloway, A. 2003. Disaster risk reduction in Southern Africa. African Security Review 12(1): 29-38.

IDNDR (International Decade for Natural Disaster Reduction). 1994. Yokohama strategy and plan of action for a safer world: Guidelines for natural disaster prevention, preparedness and mitigation. http://www.unisdr.org/files/8241_doc6841conte nido1.pdf. Accessed 6 May 2015.

IFRC (International Federation of Red Cross and Red Crescent Societies). 2010. Desk review on trends in the promotion of community-based disaster risk reduction through legislation. https://www.ifrc.org/Global/Publications/IDRL/resources/Legis lation-and-Community-level-DRR.pdf. Accessed 6 May 2015.

IPCC (Intergovernmental Panel on Climate Change). 2012. Special report on managing the risks of extreme events and disasters to advance climate change adaptation. Cambridge: Cambridge University Press.

IPCC (Intergovernmental Panel on Climate Change). 2014. Climate change 2007: The IPCC fourth assessment report. Cambridge: Cambridge University Press.

Kelman, I. 2015. Climate change and the Sendai framework for disaster risk reduction. International Journal of Disaster Risk Science 6(2). doi:10.1007/s13753-015-0046-5.

Kelman, I., J.C. Gaillard and J. Mercer. 2015. Climate change's role in disaster risk reduction's future: Beyond vulnerability and resilience. International Journal of Disaster Risk Science 6(1): 21-27.

Leal, A.P. 2007. Participation: The ascendancy of a buzzword in the neo-liberal era. Development in Practice 17(4-5): 539-548.

Manikutty, S. 1997. Community participation: So what? Evidence from a comparative study of two rural water supply and sanitation projects in India. Development Policy Review 15(2): 115-140.

Mercer, J., I. Kelman, K. Lloyd, and S. Suchet-Pearson. 2008. Reflections on use of participatory research for disaster risk reduction. Area 40(2): 172-183.

Mosse, D. 2004. Is good policy unimplementable? Reflections on the ethnography of aid policy and practice. Development and Change 35(4): 639-671.
Mpepo, B.P., and V. Seshamani. 2005. Zambia's PRSP process: From exclusion to inclusion, confrontation to cooperation? Participatory Learning in Action 51: 59-63.

Nicholson, S.E. 2014. A detailed look at the recent drought situation in the Greater Horn of Africa. Journal of Arid Environments 103: $71-79$.

OECD (Organisation for Economic Co-operation and Development). 1997. Evaluation of programs promoting participatory development and good governance. Paris: OECD.

Olowu, D. 2010. The Hyogo Framework for Action and its implications for disaster management and reduction in Africa. Jàmbá: Journal of Disaster Risk Studies 3(1): 303-320.

Parfitt, T. 2004. The ambiguity of participation: A qualified defence of participatory development. Third World Quarterly 25(3): $537-555$.

Pelling, M. 2007. Learning from others: The scope and challenges for participatory disaster risk assessment. Disasters 31(4): 373-385.

Pretty, J.N. 1995. Participatory learning for sustainable agriculture. World Development 23(8): 1247-1263.

Roncoli, C., C. Jost, P. Kirshen, M. Sanon, K.T. Ingram, M. Woodin, L. Somé, F. Ouattara, et al. 2008. From accessing to assessing forecasts: An end-to-end study of participatory climate forecast dissemination in Burkina Faso (West Africa). Climatic Change 92(3-4): 433-460.

Senaratna, N., M.-A. Baudoin, A. Oluoko-Odingo, D.W. Wepukhulu, and A.S. Mwadali. 2014. Natural hazards and climate change in Kenya: Minimizing the impacts on vulnerable communities through Early Warning Systems. In Reducing disaster: Early warning systems for climate change, ed. A. Singh and Z. Zommers, 355-375. London: Springer.

Shivernje, H. 2005. What happened to the PRSP in Kenya? The role of politics. Participatory Learning in Action 51: 27-31.

Taylor, A., A. Cartwright, and C. Sutherland. 2013. Institutional pathways for local climate adaptation: A comparison of three South African municipalities. Agence Francaise pour le Developpement Focales 18, Paris.

UNISDR (United Nations International Strategy for Disaster Reduction). 2005. Hyogo framework for action 2005-2015: Building the resilience of nations and communities to disasters. Geneva: UNISDR.

UNISDR (United Nations International Strategy for Disaster Reduction). 2010. Local governments and disaster risk reduction: Good practices and lessons learned. http://www.unisdr.org/we/ inform/publications/13627. Accessed 6 May 2015.

UNISDR (United Nations International Strategy for Disaster Reduction). 2011. Hyogo framework for action 2005-2015 mid-term review. http://www.unisdr.org/we/inform/publications/18197. Accessed 6 May 2015.

UNISDR (United Nations International Strategy for Disaster Reduction). 2012. Disaster reduction in Africa: UNISDR informsSpecial issue on drought risk reduction 2012. Geneva: UNISDR.

UNISDR (United Nations International Strategy for Disaster Reduction). 2015. Sendai framework for disaster risk reduction 2015-2030. Geneva: UNISDR.

USAID (United States Agency for International Development). 2012. Building resilience to recurrent crisis: USAID policy and program guidance. Washington, DC: USAID.

Vermaak, J., and D. van Niekerk. 2004. Disaster risk reduction initiatives in South Africa. Development Southern Africa 21(3): $555-574$

White, S.C. 1996. Depoliticising development: The uses and abuses of participation. Development in Practice 6(1): 6-15.

World Bank. 2012. Disaster risk financing and insurance in SubSaharan Africa: Review and options for consideration. 
Washington DC: The World Bank. http://www.preventionweb. net/go/31323. Accessed 11 Feb 2014.

World Bank. 2014. Learning and results in World Bank operations: How the bank learns. Results and performance of the World Bank Group 2012. Washington, DC: The World Bank.
Zia, A., and C.H. Wagner. 2015. Mainstreaming early warning systems in development and planning processes: Multilevel implementation of Sendai framework in Indus and Sahel. International Journal of Disaster Risk Science 6(2). doi:10. 1007/s13753-015-0048-3. 